\title{
NCAA Drug Testing Policies and Penalties: The Role of Team Performance
}

\author{
Kelly P. Elliott, Timothy B. Kellison, and Beth A. Cianfrone \\ Georgia State University
}

\begin{abstract}
Under National Collegiate Athletic Association (NCAA) rules, all Division I and II student-athletes are subject to year-round drug testing. In addition to these NCAA-mandated tests, the NCAA encourages each member school to establish its own drug testing policy. Drug testing has been studied frequently, often from the legal, athlete motivation, or economic perspectives. Yet, on the collegiate level, it is unclear the extent to which drug testing policies vary across institutions and divisions. Therefore, the purpose of this study was to compare the drug testing policies of high- and low-performing athletic programs to determine whether student-athletes competing on successful teams in revenue-generating sports are held to different standards than those participating on less successful athletic teams. Drug testing policies were collected from "high-performing" Division I and II athletic programs (i.e., those ranked in the top 25 in football, men's basketball, or women's basketball between 2012-2017); these policies were compared with those of "low-performing" athletic programs (i.e., those ranked in the bottom 50 of the Directors' Cup between 2012-2017). The results indicate several contrasts between high- and low-performing athletic departments in how they penalize athletes for positive drug penalties, particularly at the Division I level.
\end{abstract}

Keywords: athletic departments, enforcement, student-athlete support

According to National Collegiate Athletic Association (NCAA) rules, all Division I and II student-athletes are required to complete year-round drug testing (NCAA Sport Science Institute, 2017). If a student-athlete tests positive for a banned substance under a NCAA-mandated test, the student-athlete will lose eligibility to compete. In addition to these NCAA-mandated tests, the NCAA encourages its members to establish institutional drug testing policies. For these policies, member institutions can set their own penalties, which may range from mandatory drug education sessions to dismissal from the athletic team. Drug testing has been studied frequently, often from the legal (Pohlman \& Schawab, 2005), athlete motivation (Zenic, Stipic, \& Sekulic, 2011), or economic (Bahrke,

Elliott, Kellison, and Cianfrone are with the Department of Kinesiology and Health, Georgia State University, Atlanta, GA. Address author correspondence to Kelly P. Elliott at kmcbryan1@ student.gsu.edu. 
2015) perspectives. Yet, on the collegiate level, it is unclear the extent to which drug testing policies vary across institutions and athletic divisions.

Given the lack of uniform regulations, drug testing policies and penalties can vary across institutions and may reflect an athletic department's consideration for its student-athletes' well-being (Whitehill, Binkley, Wright, \& Dell-Pruett, 2009). For example, policies with penalties that include counseling or drug education may aid a student-athlete by offering treatment and guidance. Frequency of testing may be another deterrent to future use (Baudouin \& Szymanski, 2016). Other penalties, like suspension or expulsion, may be more punitive. Balancing the desire to win with the responsibility to support their student-athletes, in some instances, schools may turn to policies that avoid suspension or expulsion to maintain athlete eligibility (Whitehill et al., 2009).

There is a wide range of penalties enforced by NCAA institutions. For instance, the drug testing policies of the 2015 NCAA Men's Final Four basketball teams provide an example of the inconsistencies (Pells, 2015). Duke University, the University of Kentucky, and Michigan State University all required suspensions of varying lengths for a drug test infraction. A positive test at Duke imposed a 1-year minimum suspension, Michigan State mandated a 30-day suspension, and Kentucky required the student-athlete to miss $10 \%$ of his season. On the other hand, the University of Wisconsin did not mandate a suspension after the first positive drug test.

One suspected reason for the difference in penalties for banned substances across institutions is that perennially successful athletic programs may desire more lenient policies in order to maintain the eligibility of elite student-athletes, particularly among universities that reap the financial benefits associated with success in revenue-generating sports such as football or men's basketball. Based on the possibility that university administrators may value success in revenuegenerating sports more than nonrevenue-generating sports, Cooper and Weight (2011) surveyed athletic directors at Division I institutions and found that success in football and men's basketball was perceived to be key to the financial stability of their department. The authors argued that although there are very few athletic programs that turn a financial profit, many athletic directors envision successful football and basketball programs as vehicles for financial prosperity. The results of Cooper and Weight's study suggest athletic administrators may value success in revenue-generating sports more than nonrevenue-generating sports; as a result, they may institute policies designed to maintain student-athlete eligibility.

While researchers have previously studied athlete drug testing in terms of approaches to drug testing and penalties for drug test infractions, it is less clear whether the NCAA's lack of an association-wide policy mandating institutionlevel drug testing has led to a wide variance in drug testing policies across college athletics. In this study, we compare the drug testing policies of high- and lowperforming athletic programs to determine whether student-athletes competing on successful teams in revenue-generating sports are held to different standards than those participating on less successful athletic teams. Specifically, we examine the relationship between (a) an athletic program's performance in football and men's and women's basketball and (b) the school's drug testing policy. Additionally, we compare the drug testing policies of high- and low-performing athletic programs to identify the degree to which they differ based on penalties for infractions, the 
availability of second-chance opportunities, and the inclusion of educational components. Such inquiry may guide administrators when designing effective positive drug testing penalties on campus or recommending broader reforms to NCAA bylaws. As discussed in the next section, previous studies of drug testing policies have provided an important foundation to more expansive reviews of NCAA and institutional practices.

\section{Literature Review}

\section{Variance in Drug Testing Policies}

Although the NCAA conducts its own drug test screening, institutional drug testing policies are determined by the athletic department. Unsurprisingly, testing rates and penalties for failed tests can vary from institution to institution. A 2011 report from the Associated Press showed wide disparities in the drug testing policies and procedures of 51 institutions included in their sample; while some polices were very strict (e.g., calling for more frequent drug test administrations and studentathlete suspensions), others did not enforce suspensions after the first positive drug test.

The lack of a consistent testing policy can be problematic, as differences in drug testing enforcement across institutions can elicit negative reactions from student-athletes, administrators, and fans, because some drug testing policies may be viewed as overly punitive in comparison to others. The varying policies may lead to seemingly unfair advantages for some institutions, as a banned substance violation at one institution may require the offending student-athlete to sit out from competition, while the same type of violation committed at a rival institution may result in a less restrictive penalty. This perceived advantage has led some administrators to argue for more consistent drug testing guidelines. For example, Bob Copeland, former director of athletics at Waterloo University, argued, "Bottom line is, you need a common standard so you have a level playing field" (Pells, 2015, para. 21). As advocates of a uniform drug testing code have suggested, universities seeking a competitive advantage may adopt weak testing policies to protect student-athlete eligibility (Terlep, 2016). Although this strategy is permissible per NCAA bylaws, it may promote an environment in which athletic success overshadows the actual goals of the NCAA drug testing program, including deterrence and protecting "the health and safety of the student-athletes competing" (NCAA Sport Science Institute, 2017, p. 6).

An institution's athletic division (e.g., I vs. II) may similarly influence drug testing policies on campus. While NCAA Divisions I and II share the governing body's overall mission of making athletics a part of the educational experience, institutions in each division may differ in how they choose to fund their athletics programs and in the national attention they command (NCAA, 2016). In 2009, the NCAA Committee on Competitive Safeguards and Medical Aspects of Sports compiled institutional drug testing policies and procedures information from 491 institutions. Their analysis revealed a wide variance in drug testing programs across the NCAA membership, including Division I Football Bowl Subdivision, Football Championship Subdivision, and without football; Division II; and Division III institutions. Based on the NCAA report, only $16 \%$ of Division I member 
institutions suspended their student-athletes after the first positive drug test, whereas the suspension rates for first-time offenders at Division II and III institutions were 57\% and 69\%, respectively (NCAA, 2009). While the NCAA's report illustrated the degree to which suspension rates for failed drug tests differed across divisions, it offered little explanation for these disparities. In addition to suspension rates, the NCAA report also showed a wide range of penalties for the student-athlete who violated an institution's banned substance rules, including discussion with the team's athletic trainer, physician, or coach; mandatory drug education programs; referral to drug counseling; intra-squad discipline; suspension from the team; and dismissal from the team (NCAA, 2009).

With the multitude of penalties levied by each institution, further investigation is required to determine the randomness or intentionality of these disparities. In either case, institutions implementing drug testing penalties need a guide to ensure that highly-competitive sport programs maintain ethical standards, student-athlete safety, and a positive school reputation. Additionally, drug testing is designed to maintain the integrity of sport. Although the topic of drug testing student-athletes can be polarizing - particularly when it comes to issues of privacy and the banned substance list (e.g., Kessler, 2016; Sailors, Teetzel, \& Weaving, 2012)—punitive measures might be considered constructive if the intent of these policies is to prevent drug use or provide substance abuse treatment (Bahrke, 2015). The rationale and severity of drug test infractions are examined further in the next section.

\section{Penalties for Infractions}

Zero-tolerance policies. Researchers suggest that most drug testing programs in education include a zero-tolerance policy toward the use of banned substances. Schools use a variety of restrictive measures in their drug testing policies to deter drug use, including out-of-school suspensions, in-school suspensions, and expulsion. Despite the punitive measures taken by institutions through drug testing policies, there is a lack of empirical evidence to support the effectiveness of these penalties, and student-athletes may require customized intervention techniques to curb substance abuse (Agley, Walker, \& Gassman, 2012).

Stamm, Frick, and Hollie (2016) studied the rationale for punitive measures in drug testing policies. In particular, they investigated why institutional administrators chose to implement different policies, especially those associated with a zero tolerance for infractions. Some schools add a counseling component to their drug testing policy, but this measure is typically a secondary penalty to the harsher zero-tolerance policy guidelines that cause students to be removed from the school. According to Stamm et al., excluding students from school as a penalty for a positive drug test can prevent the student from benefiting from school support. That is, students can be negatively impacted when facing expulsion as they lose access to the positive adult interaction, counseling, and accountability they would receive in a school setting. One reason cited by the researchers for a drug policy is to keep a positive school environment that ensures safety and equality for all students in the school. This research suggests the intent for developing a drug policy should surround the needs of the institution, and not be specific to the individual student. There has been little research on alternatives to taking students out of school. 
Stamm et al. (2016) found that although most schools do not mandate a full suspension from school for the first positive drug testing offense, the length of suspension from a first positive drug testing offense nevertheless varied across institutions.

Out-of-school suspension is not the only form of punishment for a positive drug test, but research shows it is among the most common. For example, Waddell (2012) investigated drug testing policies at high schools and found only one school in his study imposed an in-school suspension for first-time positive drug test offenders. All other schools included in the study's sample suspended or expelled students for their first positive drug test (Waddell, 2012). Waddell suggested penalties for a second positive drug testing "capture what a school is ultimately prepared to do in response to this behavior and that the first, to the extent that is less severe, is some measure of grace being afforded to "first-time offenders", (Waddell, 2012, p. 4). Waddell indicated the importance of drug testing, but more research is needed on best practices and penalties for positive drug tests.

Counseling and drug education. Although counseling was also noted as being a part of most of the drug testing policies studied by Stamm et al. (2016), few policies mandated counseling or gave specific guidelines for conducting the counseling at the intercollegiate level. Administrators were quick to add the zero-tolerance policy to their drug programs, but research has not shown how counseling should be conducted when students test positive. Bahrke (2015) indicated more schools are only recommending drug counseling for positive drug tests, but most mandate at least a suspension. On the other hand, Stinchcomb (2008) reported that more than $90 \%$ of interscholastic athletic departments utilize an intervention approach that focuses on "redirecting student drug use" (p. 43) though counseling or rehabilitation programs.

When it comes to existing drug education programs, much of the curriculum focuses on steroid and performance enhancing drug (PED) use instead of recreational drugs. According to Thomas, Dunn, Swift, and Burns (2011), many studentathletes are unaware of the side effects of controlled substances and rely on Internet resources rather than peers (e.g., friends and coaches) for information. However, even though more student-athletes chose to get their information about drugs online, they also expressed belief they would benefit from more information about banned substances and would be most receptive from a presentation by a person with whom they could relate. Additionally, although student-athletes suggested additional education would help prevent and manage the use of banned substances, Thomas and colleagues' (2011) study also showed that athletes were more concerned about the potential penalties that could result from a positive test than the potential side effects of the drugs.

Athletic administrators must also consider the possibility that "one-size-fitsall" policies may not be the most effective approach to meeting all student-athletes' needs. For instance, Crosset, Filo, and Berger (2011) found that when athletic departments use more mainstream ethical reasoning in comparison to punitive penalties, African American student-athletes found more success. The researchers posited that as African American student-athletes entered an environment with unwritten policies and social norms that differed from those of White studentathletes, they benefitted more by nonpunitive measures after first-time drug 
offenses. Like Agley et al. (2012), Crosset et al. (2011) advocated for customized drug testing penalties based on the circumstances of individual student-athletes rather than the adoption of a single uniform policy for the entire institution.

\section{Approaches to Drug Testing}

Fairness of drug testing. Commonly assumed in the debate over policies and penalties is that drug testing at the intercollegiate level is an appropriate method to ensuring a level playing field. However, some scholars, such as Mitten (2009), have challenged this assumption, arguing that Olympic athletes such as Michael Phelps, Usain Bolt, and Eero Mäntyranta are already genetically advantaged in their designated sports without using PEDs. Characteristics such as height, red blood cell count, and flexibility give certain athletes a biological advantage. Mitten called into question the so-called fairness of other athletes trying to compete with athletes born with physical advantages. In addition to physical characteristics, financial support and location can also play a role in an athlete's ability to train at better facilities and learn from better coaches. In summary, Mitten challenged the legitimacy of "an equal playing field"; in the absence of such equity, he questioned why governing bodies prevented athletes from using steroids to reach their full potential. In response to Mitten's provocative question, Boxill (2009) argued that restricting the use of PEDs and other banned substances was necessary because they were harmful to the student-athletes taking them, they were harmful to other student-athletes who could be coerced to use them, and they threatened the integrity and nature of sport. Per Boxill (2009), "the death of ethics is the sabotage of excellence" (p. 6). In other words, sport is about fair play, and governing bodies should ensure ethical competition.

From an athletic participant perspective on the fairness of drug testing, Wilson and Potwarka (2015) studied how an athlete's passion predicted attitudes toward PEDs. The study showed athletes with more obsessive passion toward athletics had more positive attitudes toward using PEDs. Conversely, athletes with higher harmonious passion toward athletics had less permissible attitudes toward the use of PEDs. The passion an athlete had toward athletics provided an indicator of his or her view of drug use in sport.

Frequency of testing. Another common consideration when designing a drug testing protocol relates to the number of test administrations. In a recent study by Baudouin and Szymanski (2016), the researchers explored the degree to which increased drug testing deterred doping among Olympic athletes. The results indicated that in some sports, such as track and field, more frequent drug tests would be effective in deterring drug use; however, in other sports, such as cycling, additional testing did not deter doping. In cases in which there was not a negative relationship between testing frequency and doping, Baudouin and Szymanski suggested further research to determine how to discourage doping behaviors in sports where more frequent test administrations were ineffective.

In settings where testing frequency could be tied to a decrease in drug offenses, school officials may encounter other challenges that prevent them from simply instituting additional tests. First, a policy that allows for multiple test administrations per student-athlete may create an environment in which individuals feel 
targeted and persuade others to evade drug testing. For instance, Diacin, Parks, and Allison (2003) found some student-athletes felt they were tested more than others, as one student-athlete interviewed in the study noted:

I know a couple athletes have been tested more than once. And it seems like, "why are they getting tested more than once?" They've already passed. And there are people that are getting away with a lot of the stuff and never get tested. The "random" tests might not be random enough. (p. 5)

Secondly, with additional tests come additional costs (Baudouin \& Szymanski, 2016). Some college athletics departments might see the need to test but be hesitant to do so because of the added costs. These constraints are discussed further below.

Rationale and constraints for drug testing policies. Researchers have suggested the need to consider the rationale administrators use when constructing their drug testing policies. Underlying this rationale may be constraints that influence (positively or negatively) the support administrators can provide to students who test positive. Drug testing is expensive and when an administrator is setting the annual budget, it might be difficult to justify the spending on drug testing when there are other academic needs of the school (Bahrke, 2015). Contrasting the research by Bahrke, Nite (2012) indicated athletic department personnel find it hard to justify spending on student-athlete development while under the pressure to produce winning programs. Nite (2012) conducted interviews with athletic department staff at Division II institutions and found that although participants believed it was part of their responsibility to foster the overall development of student-athletes, the limited resources and pressure to produce winning programs prevented institutions from spending money outside of areas such as better facilities. Drug testing procedures and penalties can be expensive, especially when considering additional drug tests and counseling. These expenses can prevent institutions from using these penalties when a student-athlete tests positive, despite the potential benefit to the student-athlete's overall wellbeing. Despite the contrasting views of spending between Nite's and Bahrke's research, both researchers found that administrators were consciously electing not to invest in student-athlete development programs.

Research further shows only a small number of positive drug tests result from the many drug tests conducted (Bahrke, 2015). Fudala and Fields (1994) researched the reaction of nonfaculty, faculty, and students to drug testing programs and found there was a feeling of at least some support or no reaction to school drug testing, but there was no perception of strong opposition in the groups studied. This research indicates that there is no strong opposition to drug testing, and future research needs not only to analyze the need for a drug testing policy, but also the content of the policies themselves. Drug testing can be punitive, intrusive, and unreliable (Fudala \& Fields, 1994). These constraints can cause some hesitance on the part of administrators to implement harsh drug testing policies.

Fudala and Fields's (1994) research suggested students were all equally likely to undergo drug testing for probable cause. However, Yamaguchi, Johnson, and O'Malley, (2003) found it was more likely for students suspected of using drugs to be tested. These contradictions support the need for additional research into drug testing policies and procedures on campuses. More research suggested student 
attitudes and perceptions of drug use were bigger deterrents than the drug testing policy. As illustrated throughout the literature review, previous work has been limited and produced largely inconsistent findings. With this lack of an empirical foundation in mind, a primary goal in this study is to determine whether the competitiveness of a high-performing intercollegiate athletic program could influence the drug testing penalties imposed by an institution. Additional objectives are highlighted below.

\section{Research Questions}

Given the wide disparities in institutional drug testing policies, this study could aid member institutions when establishing or reforming their drug testing policies and determining best practices. Additionally, drug testing policies with more transparent justifications could help individual student-athletes understand why they are being tested and help them to appreciate why drug testing is a necessary part of sport. Previous studies have highlighted different approaches to drug testing, penalties for positive drug testing, and variances in drug testing in college athletics. However, these studies have not addressed the underlying reasons for the inconsistencies in drug testing policies. In this study, we expand upon the findings of the Associated Press (2011) report by exploring the role of program competitiveness in drug testing policies. The study was guided by the following research questions (RQs):

RQ1: What penalties for banned substance violations are most common among institutions with high- or low-performing Division I athletic programs?

RQ2: To what extent do the drug testing policies of Division I institutions with high-performing athletic programs differ from those of Division I institutions with low-performing athletic programs?

RQ3: What penalties for banned substance violations are most common among institutions with high- or low-performing Division II athletic programs?

RQ4: To what extent do the drug testing policies of Division II institutions with high-performing athletic programs differ from those of Division II institutions with low-performing athletic programs?

RQ5: To what extent do the drug testing policies of institutions with highperforming athletic programs differ between Division I and II members?

\section{Method}

To examine differences between high- and low-performing athletic programs, we used public polling data as proxies for athletic success. As a means of classifying high-performing athletic programs, we identified all Division I and II institutions that appeared in the top 25 postseason rankings in at least one of three sportsfootball, men's basketball, and women's basketball-in the past five seasons 
(i.e., for football: 2012, 2013, 2014, 2015, or 2016; for basketball: 2012-2013, 2013-2014, 2014-2015, 2015-2016, or 2016-2017). For Division I and II football and Division I basketball rankings, we used the respective Associated Press Top 25 polls; for Division II men's basketball, we used the National Association of Basketball Coaches (NABC) top 25 poll; and for Division II women's basketball, we used the Women's Basketball Coaches Association (WBCA) top 25 poll. These three sports were selected because they are among the costliest college sports to sponsor and command the highest coaches' salaries (with ice hockey; NCAA, 2015).

Low-performing athletic programs were selected using Learfield Directors' Cup rankings. The Directors' Cup rankings are calculated using a points-based system in which athletic programs are rewarded for success in a predetermined number of sports. The Directors' Cup is considered "the crowning achievement in college athletics" because it recognizes "institutions maintaining a broad-based program, achieving success in many sports, both men's and women's" (Learfield Directors' Cup, 2017, paras. 1-2). We included any institution appearing in the bottom 50 end-of-season rankings in the past five academic seasons (i.e., 2012-2013, 20132014, 2014-2015, 2015-2016, or 2016-2017). There were no cases in which an institution appeared in both the high-performing and low-performing lists.

Next, we collected these institutions' drug testing policies from their respective athletic department websites. In cases in which the policies were not publicly accessible, we contacted athletic administrators directly to request details on their policies. In sum, we collected data from 348 institutions (i.e., $n_{\text {DI-high }}=80 ; n_{\text {DI-low }}$ $\left.=107 ; n_{\text {DII-high }}=90 ; n_{\text {DII-low }}=71\right)$. Each drug testing policy was analyzed for the type of penalty (or penalties) assessed after a first, second, and third violation; these penalties included more frequent test administrations, mandated drug education or counseling meetings, suspension from the team, and dismissal from the team.

Descriptive statistics were calculated for each institutional category (i.e., Top 25 Football, Top 25 Men's Basketball, Top 25 Women's Basketball, and Bottom 50 Directors' Cup across Division I and II). Additionally, to identify differences between high- and low-performing athletic programs, we conducted a chi-squared test, the results of which are reported in the next section.

\section{Results}

As expected, the Division I institutions included in the sample tended to increase the severity of a penalty after each drug test violation. Table 1 illustrates the most common penalties for drug test infractions among Division I institutions; additionally, the table indicates the penalties in which high-performing institutions differed from low-performing institutions.

To address RQ1, we examined the most common penalties for drug infractions among high- and low-performing Division I institutions. The most common penalties for first-time offenders were increased test administrations and counseling across all institutional categories. Suspensions were employed by less than half of high-performing programs, but $65 \%$ of low-performing programs. No institution had a policy that dismissed a student-athlete from the team for a first-time offense. After a second banned substance violation, a suspension from the team was the 


\section{Table 1 Penalties for Drug Test Infractions Among NCAA Division I Institutions, Top 25 Athletic Programs Versus Bottom 50 Directors' Cup Programs, 2012-2017}

\begin{tabular}{|c|c|c|c|c|}
\hline & $\begin{array}{l}\text { Top } 25 \\
\text { Football } \\
(n=52)\end{array}$ & $\begin{array}{l}\text { Top } 25 \\
\text { M Basketball } \\
(n=43)\end{array}$ & $\begin{array}{c}\text { Top } 25 \\
\text { W Basketball } \\
(n=42)\end{array}$ & $\begin{array}{l}\text { Bottom } 50 \\
\text { Directors' Cup } \\
(n=107)\end{array}$ \\
\hline \multicolumn{5}{|l|}{ First offense } \\
\hline Increased frequency & $87 \%$ & $81 \%$ & $88 \%$ & $83 \%$ \\
\hline Counseling & $87 \%$ & $81 \%$ & $83 \%$ & $88 \%$ \\
\hline Suspension & $39 \% * * *$ & $35 \% * * *$ & $41 \% * *$ & $65 \%$ \\
\hline Dismissal & $0 \%$ & $0 \%$ & $0 \%$ & $0 \%$ \\
\hline \multicolumn{5}{|l|}{ Second offense } \\
\hline Increased frequency & $73 \%$ & $67 \%$ & $76 \%$ & $68 \%$ \\
\hline Counseling & $79 \%$ & $77 \%$ & $81 \%$ & $82 \%$ \\
\hline Suspension & $90 \%$ & $88 \%$ & $88 \%$ & $89 \%$ \\
\hline Dismissal & $0 \%$ & $2 \%$ & $2 \%$ & $7 \%$ \\
\hline \multicolumn{5}{|l|}{ Third offense } \\
\hline Increased frequency & $29 \% *$ & $23 \%$ & $21 \%$ & $14 \%$ \\
\hline Counseling & $39 \% *$ & $37 \% *$ & $41 \% * *$ & $20 \%$ \\
\hline Suspension & $44 \% *$ & $49 \% *$ & $45 \% *$ & $28 \%$ \\
\hline Dismissal & $48 \%$ & $47 \%$ & $43 \% *$ & $61 \%$ \\
\hline
\end{tabular}

Abbreviations: $\mathrm{M}=$ men's; NCAA = National Collegiate Athletic Association; $\mathrm{W}=$ women's.

Note. Asterisk(s) indicate statistically significant difference between top athletic program group (i.e., Top 25 Football, Top 25 Men's Basketball, Top 25 Women's Basketball) and the baseline group (i.e., Bottom 50 Directors' Cup). Percentages rounded to the nearest whole number.

${ }^{*} p<.05 ; * * p<.01 ; * * * p<.001$.

most common penalty among all institutions. A third violation by a student-athlete would result in a dismissal from the team in more than $40 \%$ of high-performing institutions and more than $60 \%$ of low-performing institutions.

RQ2 related to the differences between high- and low-performing Division I institutions. The results of chi-squared testing indicated statistically significant differences in several areas. For first-time offenses, nearly two-thirds of lowperforming teams suspended student-athletes for a first-time offense, while far fewer high-performing programs utilized suspension as a penalty (football: $39 \%$, $p<.001$; men's basketball: 35\%, $p<.001$; women's basketball: $41 \%, p<.01$ ). Further contrasts were reported in penalties assessed after a third test violation. Much of these differences can be attributed to the fact that low-performing programs were more likely to utilize team dismissals $(61 \%)$ than other penalties, while all four types of penalties were more evenly distributed among highperforming teams.

RQs 2 and 3 focused on Division II institutions. In response to RQ3, we evaluated the drug testing policies of high- and low-performing athletic programs, the results of which are provided in Table 2. 


\section{Table 2 Penalties for Drug Test Infractions Among NCAA Division II Institutions, Top 25 Athletic Programs Versus Bottom 50 Directors' Cup Programs, 2012-2017}

\begin{tabular}{lcccc}
\hline & $\begin{array}{c}\text { Top 25 } \\
\text { Football } \\
(\boldsymbol{n}=\mathbf{3 9 )}\end{array}$ & $\begin{array}{c}\text { Top 25 } \\
\text { M Basketball } \\
(\boldsymbol{n}=\mathbf{4 5})\end{array}$ & $\begin{array}{c}\text { Top 25 } \\
\text { W Basketball } \\
(\boldsymbol{n}=\mathbf{3 4 )}\end{array}$ & $\begin{array}{c}\text { Bottom 50 } \\
\text { Directors' Cup } \\
(\boldsymbol{n}=\mathbf{7 1})\end{array}$ \\
\hline First offense & & & & \\
Increased frequency & $74 \%$ & $62 \% *$ & $68 \%$ & $82 \%$ \\
Counseling & $80 \%$ & $78 \%$ & $77 \%$ & $83 \%$ \\
Suspension & $67 \%$ & $80 \%$ & $85 \%$ & $72 \%$ \\
Dismissal & $0 \%$ & $2 \%$ & $0 \%$ & $1 \%$ \\
Second offense & & & & $49 \%$ \\
Increased frequency & $59 \%$ & $51 \%$ & $47 \%$ & $55 \%$ \\
Counseling & $69 \%$ & $60 \%$ & $56 \%$ & $65 \%$ \\
Suspension & $80 \%$ & $76 \%$ & $77 \%$ & $34 \%$ \\
Dismissal & $8 \% * *$ & $20 \%$ & $18 \%$ & \\
Third offense & & & & $9 \%$ \\
Increased frequency & $8 \%$ & $9 \%$ & $0 \%$ & $10 \%$ \\
Counseling & $10 \%$ & $11 \%$ & $3 \%$ & $13 \%$ \\
Suspension & $10 \%$ & $11 \%$ & $18 \%$ & $48 \%$ \\
Dismissal & $59 \%$ & $53 \%$ & $50 \%$ & \\
\hline
\end{tabular}

Abbreviations: $\mathrm{M}=$ men's; NCAA = National Collegiate Athletic Association; $\mathrm{W}=$ women's.

Note. Asterisk(s) indicate statistically significant difference between top athletic program group (i.e., Top 25 Football, Top 25 Men's Basketball, Top 25 Women's Basketball) and the baseline group (i.e., Bottom 50 Directors' Cup). Percentages rounded to the nearest whole number.

$* p<.05 ; * * p<.01$.

When it comes to overall penalties for violations, a pattern for Division I institutions emerged: As the number of offenses increased, so did the severity of the penalty. One notable exception relates to the use of suspensions. Division II institutions were far quicker to suspend student-athletes for banned substance violations; in fact, institutions with high-performing men's basketball $(80 \%)$ or women's basketball programs $(85 \%)$ were more likely to suspend student-athletes after a first-time offense than low-performing programs (72\%), though these differences were not statistically significant. After a second offense, institutions across all categories utilized additional test administrations, counseling, and suspension regularly. However, there was a significant drop in these penalties for a third offense, as all institutions relied most on team dismissals.

RQ4 related to the differences in drug testing policies between high- and lowperforming programs in Division II. Unlike Division I, penalties were mostly consistent among (a) institutions with high-performing football, men's basketball, or women's basketball and (b) those with low-performing athletic programs. There were two cases in which penalties significantly differed between high-performing and low-performing programs: increased frequency after a first offense in men's 
basketball $(62 \%$ vs. $82 \%, p<.05)$ and dismissal after a second offense in football (8\% vs. $34 \%, p<.01)$.

Finally, RQ5 centered on general differences between Division I and II institutions. As discussed above, while there were a number of differences between high- and low-performing institutions at the Division I level, there were comparatively fewer differences among Division II institutions. In other words, the drug testing policies of high-performing Division I athletic programs varied from institutions with less competitive athletic programs, whereas the drug policies of high- and low-performing institutions in Division II were relatively consistent.

\section{Discussion}

The purpose of this study was to examine the relationship between intercollegiate institutions' athletic success and their drug testing policies. Specifically, the study compared the drug testing penalties of institutions based on the success of their athletic teams. Among Division I universities, the results of this study indicate that the drug testing policies of institutions with strong football, men's basketball, or women's basketball teams differ substantially from peers with less successful athletic programs. For example, after a first failed drug test, high-performing athletic programs tend to penalize student-athletes in ways that protect their eligibility (i.e., by increasing the frequency of subsequent test administrations or mandating drug or alcohol counseling rather than suspending or dismissing them from the team), while low-performing institutions suspend student-athletes at a much greater rate. Additionally, after a third violation, most low-performing institutions require the student-athlete to be dismissed from the team; on the other hand, high-performing institutions utilized other forms of punishment. Contrarily, differences in drug testing policies among Division II institutions were much less common.

Arguments supporting reforms to the NCAA's drug testing protocols point to the perceived unfairness of institution-based penalties, in which a football powerhouse could dictate more lenient penalties for drug offenses in order to keep their best players on the field (e.g., McMurphy, 2013; Murschel, 2015; Trahan, 2015; Weinreb, 2015). If a uniform policy is desired (Barnhart, 2016), the results of this study suggest administrators should primarily focus their efforts on Division I institutions. Division I institutions across all categories relied heavily on increased testing administrations or counseling for first-time drug offenses. While Baudouin and Szymanski (2016) found the threat of increased testing could be a strong deterrent to drug use in sports, it is unclear if the intent of these policies is to deter drug use, protect athlete eligibility, or something else.

Given the widespread lack of empirical investigation on this topic, it is unsurprising that the results of this study contradict some aspects of the existing literature. For example, while Stamm et al. (2016) found that a zero-tolerance policy was common among high school drug testing policies, intercollegiate institutions largely relied on "second chance" penalties for first- and secondtime offenses (with some exceptions, namely among Division II institutions). Additionally, the fact that many programs utilized additional testing administrations counters Bahrke's (2015) suggestion that the expense of drug testing might 
prevent administrators from implementing effective policies. Of course, it is possible that athletic administrators view the cost of additional drug tests as a worthwhile investment if it deters student-athletes from committing additional violations.

As discussed previously, among Division II institutions, there were few differences between high- and low-performing institutions in their reliance on increased test administrations, mandated counseling sessions, or suspensions or dismissals from the team. Conversely, at the Division I level, universities with more successful athletic programs had policies with more lenient penalties for suspension after each round of positive drug tests. It remains unclear whether administrators are deliberate when designing drug testing policies, and future research is necessary to determine whether a uniform policy enforced by the NCAA would improve student-athlete wellness, curb the use of banned substances, and uphold the standards of fair play any better than the existing system.

The NCAA conducts year-round drug testing and student-athletes are subject to suspension from competition for positive results. In addition to the NCAA policy, the NCAA recommends member institutions have their own drug testing policies. Member institutions are not required to meet any guidelines when creating their institutional policy; however, they are required to follow their own policy and are subject to sanctions for failure to do so. As finances, studentathlete well-being, and the competitive spirit of sport can impact an institution's drug testing policy, it is paramount that university administrators develop a drug testing policy that addresses the needs of their institution and student-athletes. The results of this study represent an initial survey of current practices among the NCAA's most successful (and unsuccessful) athletic departments; additional inquiry can arm athletic administrators with the knowledge to implement more effective drug testing policies and procedures. In the concluding section, we outline the limitations of the current study and provide several suggestions for future research.

\section{Limitations and Directions for Future Research}

As an initial investigation of drug testing policies and the impact of program competitiveness, four categories of penalties were assessed; however, we acknowledge institutional differences exist in testing processes and within the categories. The number of student-athletes tested from each member institution yearly may differ. The frequency of testing, types of counseling, and duration of suspensions could differ in severity. For example, this study did not take into account the length of a suspension. Institution suspensions can range from less than one game to an entire season; in this study both lengths were considered the same suspension.

Additionally, in some cases, an institution may have separate penalties depending on whether a banned substance violation is related to PEDs or recreational drugs. In the few cases in which an institution included in this study had two distinct policies, we reported the penalties for violations associated with recreational drug use. Should a larger number of institutions begin distinguishing between PED and recreational drug violations, subsequent analyses may be conducted to determine the degree to which these separate policies contribute to institutional differences. 
A professional in the field should also take into consideration the expenses associated with maintaining a rigorous drug testing policy. For instance, of the four types of penalties analyzed in this study, increased test administrations and mandated counseling sessions are associated with additional costs. Drug testing policies that require student-athletes to participate in mandatory drug education and counseling sessions could be more expensive and out of reach for institutions with limited funding for such programs (Grasgreen, 2012; Pilon, 2013). In this study, we did not differentiate between policies in which the cost of drug treatment is the responsibility of the student-athlete or the institution (e.g., Georgia State University, 2017).

The results presented in this paper suggest that while some top-performing institutions have less punitive penalties compared to their lower-performing institution counterparts, in other top-performing institutions there is no evidence of such differences. Division I and II top-performing institutions show some consistency in terms of penalties for first, second, and third positive drug offenses, but further research can examine with greater precision the effectiveness of penalties and the positive impact the penalties have for the institutions and student-athletes. This line of inquiry can help institutions identify best practices and help administrators make decisions when it comes to drug testing policies and procedures on campus.

\section{References}

Agley, J., Walker, B.B., \& Gassman, R.A. (2012). Adaptation of alcohol and drug screening, brief intervention and referral to treatment (SBIRT) to a department of intercollegiate athletics: The COMPASS project. Health Education Journal, 72, 647-659. doi:10. $1177 / 0017896912456337$

Associated Press. (2011, March 30). Survey: College drug-testing programs vary widely. USA Today. Retrieved from http://usatoday30.usatoday.com/sports/college/2011-0330-ncaa-drug-testing_N.htm

Bahrke, M.S. (2015). Drug testing US student-athletes for performance-enhancing substance misuse: A flawed process. Substance Use \& Misuse, 50, 1144-1147. PubMed doi:10.3109/10826084.2015.1010832

Barnhart, T. (2016, May 5). Should the NCAA (or SEC) have a uniform marijuana policy? Gridiron Now. Retrieved from http://gridironnow.com/sec-ncaa-marijuana-policy/

Baudouin, C., \& Szymanski, S. (2016). Testing the testers: Do more tests deter athletes from doping? International Journal of Sport Finance, 11, 349-363.

Boxill, J. (2009). Comments of Matthew Mitten's "Rules limiting athletic performance or prohibiting athletic participation for health reasons: Legal and ethical considerations." Journal of Intercollegiate Sport, 2, 114-119. doi:10.1123/jis.2.1.114

Cooper, C., \& Weight, E. (2011). Investigating NCAA administrator values in NCAA Division I athletic departments. Journal of Issues in Intercollegiate Athletics, 4, 74-89.

Crosset, T., Filo, K., \& Berger, J. (2011). Ethics matter: Ethical orientations and disparate racial elite collegiate athletic programs. Journal of Issues in Intercollegiate Athletics, 4 , 149-170.

Diacin, M., Parks, J., \& Allison, P. (2003). Voices of male athletes on drug use, drug testing, and the existing order in intercollegiate athletics. Journal of Sport Behavior, 26(1), $1-16$. 
Fudala, P., \& Fields, L. (1994). An examination of current and proposed drug-testing policies at US colleges and universities. Journal of American College Health, 42, 267-270. PubMed doi:10.1080/07448481.1994.9936358

Georgia State University. (2017). Student-athlete handbook 2017-8. Retrieved from http:// www.georgiastatesports.com/pdf9/5454607.pdf?DB_OEM_ID=12700

Grasgreen, A. (2012, September 27). High-stakes test you can't prep for. Inside Higher Ed. Retrieved from https://www.insidehighered.com/news/2012/09/27/more-collegesusing-random-drug-testing-athletes

Kessler, M. (2016). Let's give it arrest: Why the NCAA should adopt a uniform disciplinary policy. Marquette Sports Law Review, 26, 433-456.

Learfield Directors' Cup. (2017). About. Retrieved from http://thedirectorscup.com/ about/

McMurphy, B. (2013, May 30). Drug testing in SEC hot topic. ESPN. Retrieved from http:// www.espn.com/college-football/story/_id/9324675/sec-officials-discuss-leaguewidedrug-testing

Mitten, M. (2009). Rules limiting athletic performance or prohibiting athletic participation for health reasons: Legal and ethical considerations. Journal of Intercollegiate Sport, 2 , 99-113. doi:10.1123/jis.2.1.99

Murschel, M. (2015, October 19). NCAA pushes to end marijuana testing, suspensions in favor of treatment. Orlando Sentinel. Retrieved from http://www.orlandosentinel.com/ sports/nfl/os-ncaa-pushes-end-marijuana-testing-20151018-story.html

NCAA. (2009). 2009 survey: Member institution's drug-education and drug-testing programs [data file]. Retrieved from www.ncaa.org/sites/default/files

NCAA. (2015). NCAA Division I intercollegiate athletics programs reports: 2004-2014. Retrieved from www.ncaa.org/sites/default/files/2015\%20Division\%20I\%20RE\% 20report.pdf

NCAA. (2016). About the division. Retrieved from http://www.ncaa.org/about?division=d2

NCAA Sport Science Institute. (2017). NCAA drug-testing program. In M. Wilfert (Ed.), NCAA drug-testing program: 2017-18 (pp. 6-15). Retrieved from www.ncaa.org/ sites/default/files/SSI2017-18\%20Drug\%20Testing\%20Program\% 20Protocol_20170724.pdf

Nite, C. (2012). Challenges for supporting student-athlete development: Perspectives from an NCAA Divisions II athletic department. Journal of Issues in Intercollegiate Athletics, 5, 1-14.

Pells, E. (2015, April 2). Technical foul: Final Four teams operate under 4 distinct sets of anti-doping rules, penalties. US News. Retrieved from www.usnews.com/news/sports/ articles/2015/04/02/final-four-teams-have-4-different-sets-of-drug-testing-rules

Pilon, M. (2013, January 6). Drug-testing company tied to N.C.A.A. stirs criticism. The New York Times, p. SP1.

Pohlman, K., \& Schawab, N. (2005). What are the odds? Random drug testing of students: two perspectives. The Journal of School Nursing, 21(3), 176-176. doi:10.1177/ 10598405050210030901

Sailors, P.R., Teetzel, S.J., \& Weaving, C. (2012). The complexities of sport, gender, and drug testing. The American Journal of Bioethics, 12, 23-25. PubMed doi:10.1080/ 15265161.2012.680541

Stamm, M.E., William, C.F., \& Mackey, H.J. (2016). An analysis of U.S. student drug and alcohol policies through the lens of a professional ethic for school leadership. International Journal of Education Policy \& Leadership, 11, 1-22.

Stinchcomb, R.A. (2008). Drug testing in the world of interscholastic athletics. Coach \& Athletic Director, 78(3), 39-45.

Terlep, S. (2016, March 24). The NCAA's drug problem. The Wall Street Journal. Retrieved from https://www.wsj.com/articles/the-ncaas-drug-problem-1426792929 
Thomas, J., Dunn, M., Swift, W., \& Burns, L. (2011). Illicit drug knowledge and information-seeking behaviors among elite athletes. Journal of Science and Medicine in Sport, 14, 278-282. doi:10.1016/j.jsams.2011.02.001

Trahan, K. (2015, October 14). Will Grier's PED suspension is another example of why college athletes need a union. VICE Sports. Retrieved from https://sports.vice.com/ en_us/article/bjvye3/fake-news-yankees-stage-elaborate-mock-interview-to-celebratehome-run.

Waddell, G.R. (2012). Adolescent drug use and the deterrent effect of school-imposed penalties. Economics of Education Review, 31, 961-969. doi:10.1016/j.econedurev. 2012.07.002

Weinreb, M. (2015, October 14). College football is probably juiced, but does anyone really care? VICE Sports. Retrieved from https://sports.vice.com/en_us/article/78y5zx/ college-football-is-probably-juiced-but-does-anyone-really-care

Whitehill, W., Binkley, H., Wright, K., \& Dell-Pruett, M. (2009). The drug testing process. Strength and Conditioning Journal, 31(6), 28-37. doi:10.1519/SSC. 0b013e3181ba18ff

Wilson, A., \& Potwarka, L. (2015). Exploring relationships between passion and attitudes toward performance enhancing drugs in Canadian collegiate sport contexts. Journal of Intercollegiate Sport, 8, 227-246. doi:10.1123/jis.2014-0093

Yamaguchi, R., Johnson, L., \& O’Malley, P. (2003). Relationship between student illicit drug use and school drug-testing policies. Journal of School Health, 73(4), 159-164 PubMed doi:10.1111/j.1746-1561.2003.tb03596.x

Zenic, N., Stipic, M., \& Sekulic, D. (2011). Religiousness as a factor of hesitation against doping behavior in college age athletes. Journal of Religion and Health, 52, 386-396. doi:10.1007/s10943-011-9480-x 